\title{
Salientando marginalidades. A Função dos ePITEXTOS Na literatura de PAsolini TRADUZIDA NO BRASIL
}

\author{
Lucas Sousa Serafim \\ ANDrea SANTURBano*
}

\begin{abstract}
RESUMO: A voz de Pier Paolo Pasolini é considerada uma das mais importantes do século XX. Em seus dois romances iniciais, Meninos da vida (1955) e Uma vida violenta (1959), se destaca uma atenção especial aos elementos da marginalidade: seus protagonistas não ocupam lugares privilegiados nos centros urbanos, é valorizado o uso de dialetos e cenas de violência são consideradas como naturais. $\mathrm{O}$ aspecto da marginalidade e da violência, sobretudo, é o viés pelo qual Pasolini ganha visibilidade no Brasil, em epitextos como resenhas, notícias, entrevistas, etc. Esta comunicação pretende refletir sobre a função dessas publicações, sobre o diálogo que elas estabelecem com os livros do autor italiano e como elas auxiliam o entendimento das características de suas obras literárias no Brasil.
\end{abstract}

PALAVRAS-CHAVE: Pier Paolo Pasolini; violência; epitexto.

ABSTRACT: Pier Paolo Pasolini è considerato uno degli autori più importanti del Novecento. Nei suoi primi due romanzi, Ragazzi di vita (1955) e Una vita violenta (1959) spicca una particolare attenzione per gli elementi marginali: i protagonisti non occupano luoghi privilegiati nei centri urbani, è valorizzato l'uso di dialetti e le scene di violenza sono considerate naturali. Soprattutto l'emarginazione sociale e la violenza sono gli aspetti per cui Pasolini acquisisce visibilità in Brasile, in

* Universidade Federal de Santa Catarina, Florianópolis (Brasil) - lucass.serafim@gmail.com / andreasanturbano@ gmail.com

Processo n.2013/20971-0 Fundação de Amparo à Pesquisa do Estado de São Paulo (FAPESP)

DOI: http://dx.doi.org/10.11606/issn.2238-8281.v0i33p130-136 
epitesti quali recensioni, articoli, interviste, ecc. In questo articolo ci si propone di riflettere sulla funzione di queste pubblicazioni e sul loro dialogo con i libri dell'autore italiano, per comprendere in che modo possono essere d'ausilio per la comprensione delle caratteristiche delle sue opere letterarie in Brasile.

PAROLE CHIAVE: Pier Paolo Pasolini; violenza; epitesto.

ABSTRACT: Pier Paolo Pasolini's voice echoes as one of the most important of the 20th century. His first two novels - Ragazzi di vita (1955) and Una vita violenta (1959) - turn an attentive look towards the marginalized elements of society: his protagonists don't belong to privileged spaces of the urban centers, the use of dialects is valued and violent scenes are presented as natural. The aspects of marginality and violence are the main reasons why Pasolini earns visibility in Brazil, through epitexts such as reviews, news articles, interviews, and so on. This article intends to reflect on the role of these publications, the dialog they establish with the Italian author's books, and how they assist on the understanding of his literary body of work in Brazil.

KEYWORDS: Pier Paolo Pasolini; violence; epitext. 


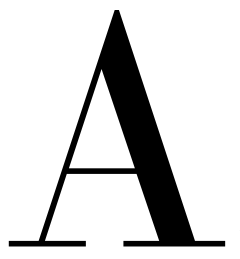

violência, ao longo dos séculos, foi tão comum que beiramos o ponto em que algumas atitudes deixaram de causar espanto e começaram a ser consideradas como naturais. No contexto de violência sempre há uma relação de opressão, representada por uma pessoa que ocupa o lugar de oprimida e por quem ocupa o lugar de opressor.

Considerado pela crítica como uma das vozes mais transgressoras do século passado, Pier Paolo Pasolini (1922 - 1975) soube como fazer da literatura ${ }^{1}$ um modelo de entendimento da realidade. O modo como retratou, corajosamente, as mazelas do pós-guerra italiano lhe rendeu destaque no cenário cultural. Como o autor não se restringiu ao seu território nacional, alcançando realce global, no Brasil ele foi muito valorizado pela editora Brasiliense - editora que, desde sua fundação explicitou seu perfil: caráter político de esquerda e marxista, tentativa de revelar problemas sociais brasileiros, investimento em publicações pouco prestigiadas, etc.

Os dois primeiros romances publicados por Pasolini foram Ragazzi di vita (1955) e Una vita violenta (1959). Riccetto, protagonista de Meninos da vida, jamais ocupou lugar de destaque na

1 Destaco que Pier Paolo Pasolini desenvolveu diversos modos de expressão: foi ensaísta, dramaturgo, poeta, romancista e também foi um grande cineasta. Optou pela linguagem do cinema por defender que as imagens comunicam de modo mais universal que as palavras. Entretanto, para este texto, me valho principalmente de sua trajetória literária. Vale lembrar que ecos de sua caminhada pela sétima arte são notados no movimento do Cinema Novo Brasileiro - destaco aqui o nome de Glauber Rocha - um de seus amigos. 
sociedade, cometia pequenas contravenções para sobreviver. Ao longo da narrativa, percebe-se que sua constante peregrinação não vislumbra mudança para sua condição social de oprimido. $\mathrm{O}$ outro romance também representa a periferia romana. Uma vida violenta apresenta um grupo de amigos fadado ao entre-lugar. Tommaso e seus amigos não são crianças mas não são adultos; não ocupam o centro mas não estão no cerne dos excluídos.

A opção do autor pelo uso do calão, da linguagem urbana e da linguagem interna de certos grupos (as quais em outro contexto deixam de fazer sentido) evidencia traços próprios da violência advindos da linguagem. Ora, certamente esses tipos de linguagem apresentam especiais dificuldades de tradução. Contudo, o momento em que as obras literárias pasolinianas ganham maior destaque no Brasil é propício até para a recriação dessas linguagens, como veremos graças à análise dos epitextos criados em torno a essas obras nos anos 1960 e 70.

Lembramos que, segundo a definição de Gérard Genette, o epitexto "é todo elemento paratextual que não se encontra anexado materialmente ao texto no mesmo volume, mas que circula de algum modo ao ar livre, num espaço físico e social virtualmente limitado" (GENETTE, 2009, p. 303). Portanto, o lugar do epitexto é fora do livro. O epitexto é um dos elementos mais importantes para se avaliar a recepção de uma obra em um novo contexto, e por isso nos propomos a observar alguns epitextos que se formaram no Brasil, em torno da obra de Pier Paolo Pasolini.

Inicialmente Pasolini ultrapassa as fronteiras italianas por meio do cinema, sua obra é recebida em vários países; no Brasil não seria diferente. Em 1968 o autor tem seu primeiro livro traduzido no Brasil (A hora depois do sonho - Il sogno di una cosa, 1962); na quarta capa, Maria Betânia Amoroso observa que o livro é a "incursão de um famoso cineasta no terreno do romance [...]" e que o livro será certamente bem acolhido no Brasil por quem já assistiu um filme do mesmo autor" (AMOROSO, 2007, p. 80). Em paralelo a tudo isso, aqui no Brasil um movimento literário vai ganhando visibilidade. Os contos de autores como Rubem Fonseca e Dalton Trevisan, os quais foram publicados nas décadas de 1960 e 70, estavam colocando em cena personagens outrora esquecidos, como por exemplo prostitutas, bandidos, policiais corruptos, mendigos, ou até mesmo pessoas aparentemente comuns que praticavam roubos ou violência física contra outras. Alfredo Bosi (BOSI, 1975) batiza esse movimento como "literatura brutalista". No instante em que o primeiro livro de Pasolini é publicado no Brasil, o terreno artístico local já está preparado para as cenas transgressoras. Meninos da vida e Uma vida violenta são publicados no Brasil na década de 1980, ápice do movimento da literatura 
brutalista. Tanto nestas duas obras italianas destacadas, quanto no movimento artístico literário brasileiro, o sentimento de banalização da barbárie se instaura, passando a ser mais difusa, irracional e performativa.

Embora estas obras de Pasolini exponham características extremamente difíceis de serem abordadas em suas traduções no Brasil, o cenário cultural local tornava-se mais receptivo para tais obras. Passando pelas personagens socialmente excluídas dos centros, o autor também se vale da observação do exercício da sexualidade das mesmas. Certamente que esta exploração acerca do tema da sexualidade segue a linha da transgressão (tomo como exemplo máximo o filme Salò ou os 120 dias de Sodoma); já na década de 1970, em alguns filmes, expõe cenas de sexo com luz e nus frontais masculinos. Luiz Nazario, um dos mais importantes conhecedores das obras de Pasolini no Brasil, destaca a importância de olhar para as obras de Pasolini numa época (década de 1980) em que a violência de massa se tornou uma das realidades cotidianas globais, cujo aumento de criminalidade, evidência da destruição dos valores humanos e dilapidação dos recursos naturais, entre outras características que, há meio século, a obra pasoliniana já vinha destacando. Segundo Nazario, um dos primeiros artistas a vislumbrar e demonstrar artisticamente essa mudança de valores foi Pasolini. Embora seja um autor conhecido e cujo destaque global se evidencia, Nazario não acredita que seja possível, atualmente, avaliar o legado que o artista italiano deixou (NAZARIO, 2007).

Pier Paolo Pasolini minimizou a barreira entre marginais e intelectuais. Colocando as pessoas excluídas no centro de sua ficção, ele dava visibilidade a elas; em seus filmes, optou pelo recrutamento de atores diversos dos habituais: como por exemplo as pessoas comuns da periferia romana contracenando com a cantora lírica Maria Callas (em Medea - 1969). Ao demonstrar que os abismos podem ser minimizados, dialogava intimamente com as necessidades da cultura brasileira, por exemplo. As obras literárias pasolinianas, sobretudo aquelas que destacavam a violência como modus operandi, encontrava ressonância no movimento da literatura brutalista.

Assim como o artista italiano, a cultura brasileira também começou a buscar inspiração na literatura para realização de películas cinematográficas. Muito embora esse movimento não seja algo inovador, o que há de diferente de outras épocas é que a violência própria dos livros não ficou restrita à primeira linguagem, isto é, foi recuperada também nos filmes. Citarei três obras para exemplificar: Carandiru, 2003, filme dirigido por Hector Babenco, baseado no livro Estação Carandiru (1999), de Drauzio Varella; Cidade de Deus, 2002, adaptação roteirizada por Bráulio Mantovani a partir do livro homônimo escrito por Paulo Lins, dirigido por Fernando Meirelles; 
e um outro tipo de violência que vale lembrar, $O$ auto da Compadecida, 2000, dirigido por Guel Arraes, filme baseado na peça teatral homônima escrita por Ariano Suassuna, na qual a violência aparece como se fosse uma instância estrutural, contra a qual há pouca reação.

O primeiro filme que Pier Paolo escreveu e dirigiu sozinho foi Accattone, no Brasil traduzido como Desajuste Social. Lançado em 1961, contou com a assistência de direção de Bernardo Bertolucci. É interessante notar que Accattone apresenta pessoas oprimidas pelo sistema social no qual estão inseridas: o protagonista que dá nome ao filme é um cafetão vivendo em Roma durante a década de 1960, ele explora a prostituta Madalena; no decorrer dos fatos, ela é presa por perjúrio e ele se vê sem recursos financeiros. Destaco que este filme é resultado da inspiração de dois romances, quais sejam, Ragazzi di vita e Una vita violenta.

Portanto, tanto Pier Paolo Pasolini, quanto o cenário cultural brasileiro do momento de sua recepção, se nutriam de ferramentas semelhantes: cenas de violência, pessoas oprimidas, pessoas socialmente marginalizadas, além do diálogo e tentativa de transpor esses elementos da literatura para o cinema.

Em seu mais recente livro sobre o autor italiano (Nazario, 2007), Luiz Nazario dedica um capítulo à recepção das obras pasolinianas no Brasil. Entretanto, o autor destaca que embora tenha encontrado um bom terreno para suscitar diálogos acerca das pessoas excluídas e seus movimentos transgressores em busca de vez e voz, recentemente o artista italiano experimenta marcas de uma negatividade e, provavelmente, um paulatino esquecimento. Isso pode ser resultado da influência de uma onda conservadora que atravessa nosso país. Momento no qual, certamente as experiências mais transgressoras vão sendo, pouco a pouco, desprestigiadas.

Conquanto essa força do esquecimento atraia, a resistência permanece. Há menos de cinco anos atrás, um grupo iniciou um projeto para encenar o monólogo Pasolini, a vida depois do sonho; dirigido por Edson Bueno e contando com a atuação de Elder Gattely, o processo criativo deste monólogo conta com várias características da obra pasoliniana. Também vale destacar que os filmes de Pasolini são constantemente apresentados em diversas mostras cinematográficas no país. Além disso, no ano passado (2015), a editora Cosac Naify publicou um livro organizado por Maurício Santana Dias e Alfonso Berardinelli, intitulado Poemas: Pier Paolo Pasolini, que apresenta em edição bilíngue 46 textos de autoria de Pasolini. E, para finalizar, em janeiro deste ano de 2016, o "Grupo XIX de teatro" estreou sua nova peça Teorema 21, dirigida por Luiz Fernando Marques e cuja dramaturgia é de Alexandre Dal Farra. A peça foi inspirada na obra Teorema, é encenada em uma antiga escola visando à ocupação dos espaços urbanos (também 
se preocupando com acessibilidade), e contou com entrada gratuita para maior abrangência de público.

Certamente que os epitextos amparam a compreensão de um texto, e, sobretudo, no que diz respeito à nossa pesquisa, a compreensão da recepção daquele texto, ou seja, do diálogo que se estabeleceu entre aquele texto e o contexto de chegada. Tanto artigos ou livros - como, por exemplo, os de Maria Betânia Amoroso e Luiz Nazario -, como adaptações cinematográficas - no caso de Accattone: Desajuste Social -, conjuntamente com projetos atuais - seja dramatúrgicos, seja exibições cinematográficas - auxiliam na compreensão desse diálogo.

Vários motivos contribuem para prolongar o interesse pelas obras de Pasolini no Brasil. Dentre tantos, destaco principalmente dois: um deles é a maneira como as traduções se desenvolvem e sobretudo o cuidado de prestigiar particularidades que ultrapassam os limites da questão linguística e, deste modo, proporciona trânsitos de comunicação entre os sistemas culturais diferentes. E o outro motivo - o tema deste artigo - é a função dos epitextos, estes que circundam a obra e que buscam ressaltar esses diálogos e pontos de contato entre as culturas.

\section{Referências:}

AMOROSO, Maria Betânia, “As periferias do mundo. Pasolini e o Brasil”, in Via Atlântica (Dez/2007), n. 12, pp. 79-94.

BOSI, Alfredo. O conto brasileiro contemporâneo. São Paulo: Cultrix, 1975.

GENETTE, Gérard. Paratextos editoriais. Tradução Álvaro Faleiros. Cotia-SP: Ateliê Editorial, 2009. NAZARIO, Luiz. Todos os corpos de Pasolini. São Paulo: Perspectiva, 2007.

Recebido em 07/05/2017

Aprovado em 17/07/2017 